\title{
Un programa de alfabetización visual para el uso y distribución de fotografías: la epistemología visual en el núcleo de una corporación privada
}

\section{Resumen}

Este artículo estudia, desde una perspectiva histórica, el caso de un programa singular de alfabetización visual desarrollado por la Photographic Section de la compañía petrolera Standard Oil Company (New Jersey), entre 1943 y 1950. El objetivo principal es describir y analizar un conjunto de rasgos y características de ese proceso epistémico, partiendo del abordaje de las propias técnicas, reglas, instrucciones, recomendaciones y procedimientos de alfabetización visual para el uso de las fotografías, en el marco de un sofisticado sistema de distribución que se adecuó a una estrategia de comunicación visual, inédita en la historia de la comunicación corporativa, en las relaciones públicas en la industria. El enfoque metodológico, de tipo documental cualitativo soportado en fuentes primarias, establece un esquema relacional entre dos metadocumentos textuales y visuales de capacitación y entrenamiento visual, The Use of Photographs y Training Program, y un corpus amplio de documentos que permite comprender, como se logra concluir en el artículo, la conceptualización epistémica del esquema de alfabetización visual, los rasgos de su funcionamiento institucional, la descripción y el examen de las transformaciones de las técnicas propias del dispositivo de conocimiento visual que ponía a prueba, y las formas y modos de difusión y distribución de los resultados.

\author{
Edward Goyeneche-Gómez \\ Doctor en Historia. \\ Profesor, Universidad de La Sabana, \\ Bogotá, Colombia. \\ Correo electrónico: edward. \\ goyeneche@unisabana.edu.co \\ ๑ orcid.org/0000-0003-0746-4310 \\ Google Scholar
}

Recibido: marzo 12 de 2021

Aprobado: agosto 20 de 2021

\section{Palabras clave:}

epistemología visual, fotografía, alfabetización visual, educación, comunicación visual. 


\section{A visual literacy program for the use and distribution of photographs: visual epistemology of the core of a private corporation}

\begin{abstract}
This article studies, from a historical perspective, the case of a unique visual literacy program developed by the Photographic Section of the Standard Oil Company (New Jersey) between 1943 and 1950. The main objective is to describe and analyze a set of features and characteristics of this epistemic process based on the approach of the techniques, rules, instructions, recommendations and procedures of visual literacy for the use of photographs within the framework of a sophisticated distribution system that was adapted to a visual communication strategy, unprecedented in the history of corporate communication in public relations in the industry. The methodological approach, of a qualitative documentary type supported by primary sources, establishes a relational scheme between two textual and visual metadocuments of training and visual training, The Use of Photographs and Training Program, and a wide corpus of documents that allows understanding, as it is possible to conclude in the article, the epistemic conceptualization of the visual literacy scheme, the features of its institutional functioning, the description and examination of the transformations of the techniques of the visual knowledge device that it was putting to test, and the forms and modes of diffusion and distribution of the results.
\end{abstract}

Key words:

visual epistemology, photography, visual literacy, education, visual communication. 


\section{Introducción}

Un filme de diapositivas titulado The Use of Photographs (Standard Oil Company (New Jersey), n.d.-a), y un manual de instrucciones Ilamado Training Program (Standard Oil Company (New Jersey), n.d.-b) son los dos documentos, producidos y utilizados entre 1943 y 1950, que sintetizan el programa de capacitación y entrenamiento visual desarrollado por la Photographic Section de la Standard Oil Company (New Jersey) — SONJ_- para redefinir y reconducir los procesos de comunicación entre la compañía y sus públicos, internos y externos, durante los años 40 del siglo XX, como parte de un esfuerzo institucional para mejorar su imagen. La construcción del archivo fotográfico, creado y dirigido por Roy E. Stryker, incluyó la elaboración de una extensa y rigurosa documentación, de naturaleza epistémica, para socializar el conjunto de políticas de representación y archivo para el uso de la fotografía, aplicadas en todo el proceso de creación, edición, difusión y utilización de las imágenes.

Este artículo avanza en la investigación del caso del archivo fotográfico de la SONJ cuyo poder, sentido y contexto se estudió previamente en otras publicaciones en las que se examinó, por una parte, como un dispositivo discursivo y narrativo para redefinir el papel de la industria del petróleo en la sociedad global y modificar el régimen de representación visual de la época, insertando culturas y comunidades marginadas a un nuevo campo escópico (Goyeneche-Gómez, 2020). Y, por otro lado, como un proyecto revolucionario de relaciones públicas que buscaba la construcción de un nuevo mito sobre el capitalismo transnacional (Goyeneche-Gómez, 2021).

Nos centramos, ahora, en el análisis de lo que podría denominarse un programa singular de alfabetización visual, siguiendo la noción de James Elkins (2003, pp. 136-137), que surgió y se adecuó a una estrategia, inédita en la historia de la comunicación corporativa, de uso de la fotografía en las relaciones públicas 
en la industria. Se conjuga, en este artículo, la noción de alfabetización visual, que parte de la premisa de entender cómo las personas perciben los objetos, interpretan lo que ven y lo que aprenden (Elkins, 2008, p. 2), con la idea de una epistemología de la visualidad, construida por José Luis Brea (2005), que articula la relación entre procesos históricos de representación y conocimiento con dispositivos y operadores epistémicos que dependen de procesos de socialización y aprendizajes de técnicas asociadas a lo visual (p. 9).

Los dos documentos, en torno a los cuales centramos el análisis, se constituyen en un dispositivo de entrenamiento y educación visual que sintetiza todo el sentido institucional del modelo epistemológico que se estaba poniendo en funcionamiento. La Photographic Section de la SONJ logró tejer una red heterogénea, efectiva y sofisticada de prácticas, instituciones y discursos para poner a circular imágenes fotográficas, bajo la premisa de capacitar a todos los actores implicados en el uso de este tipo de lenguaje:

El Uso de Fotografías

La Compañía Jersey ha preparado una película de diapositivas como un dispositivo de capacitación para ilustrar cómo las fotografías pueden ser usadas. Las siguientes páginas reproducen la secuencia seguida en la película.

Esta película explica el amplio uso - y también las limitaciones - de la fotografía en las relaciones públicas en la industria. (Standard Oil Company (New Jersey), n.d.-a, traducción propia)

\section{Discusión conceptual y metodológica}

La noción de uso, insertada al propio vocabulario del esquema de la SONJ y que ha sido fundamental para el estudio de lenguajes, de representaciones, de campos y prácticas artísticas, pocas veces se encuentra tan históricamente definida como en el caso de este programa de capacitación visual. El concepto de uso ha sido construido teórica y empíricamente por autores como Pierre Bourdieu, Ernst Gombrich o Ludwig Wittgenstein para analizar el problema de 
los significados y las significaciones sociales y culturales. La noción de uso en el caso de Bourdieu (2003) depende del espacio social en el cual una práctica artística se desarrolla en virtud de la configuración de relaciones sociales, culturales, económicas y políticas en las cuales los sujetos o las instituciones están implicados (p. 41).

En una línea funcional similar, para Gombrich (2002) "lo que Ilamamos 'ver' está condicionado por los hábitos y las expectativas" (p. 77). Los usos de las imágenes dependen, en ese sentido, de la función que se espera que desempeñe una imagen en una sociedad (Gombrich, 2003). En la producción de imágenes se juega la relación entre funciones y necesidades por lo que todos los elementos formales de una fotografía acompañan a la función. Gombrich coincide con Wittgenstein, de manera más fenomenológica, en que el significado de una representación concreta es su uso, el cual determina el sentido y la forma de todo lo que existe en los juegos de lenguaje que son reglados (Wittgenstein, 1999). Pero, además, para Gombrich (2002) lo visual se relaciona con las categorías propias del conocimiento humano en un contexto histórico determinado: "nunca podremos separar tajantemente lo que vemos de lo que sabemos" (p. 331).

En este sentido, desde la noción de epistemología visual, los usos dependen, como lo señala Brea (2005), de los actos de ver:

(...) que resultan de la cristalización y amalgama de un espeso trenzado de operadores (textuales, mentales, imaginarios, sensoriales, mnemónicos, mediáticos, técnicos, burocráticos, institucionales...), y de un no menos espeso trenzado de intereses de representación en liza: intereses de raza, género, clase, diferencia cultural, grupos de creencias o afinidades, etcétera. (p. 9)

Para Brea, entonces, es fundamental, en el estudio de la epistemología visual, analizar las arquitecturas abstractas, en sus concreciones materializadas como articulaciones históricas efectivas, que determinan al mismo tiempo lo que es 
visible y lo que es cognoscible; y que funcionan, además, políticamente, es decir, de acuerdo a una distribución disimétrica de posiciones de poder en relación con el propio ejercicio del ver (pp. 10-11).

La noción de epistemología visual estaría, en este sentido, soportada en la propia concepción de visión de W. J. T. Mitchell (2003):

(...) la visión es (como así decimos) una "construcción cultural", que es aprendida y cultivada, no simplemente dada por la naturaleza; que, por consiguiente, tendría una historia relacionada —en algún modo todavía por determinar - con la historia de las artes, las tecnologías, los media, y las prácticas sociales de representación y recepción; y (finalmente) que se haya profundamente entreverada con las sociedades humanas, con las éticas y políticas, con las estéticas y la epistemología del ver y del ser visto. (p. 19)

En este sentido, el concepto de epistemología visual se conecta con el concepto de alfabetización visual, según la línea mencionada de Elkins, desde la idea de que ambos son subsidiarios y están asociados, a veces de manera contradictoria y paradójica, a muchos de las nociones de los estudios visuales que se han centrado en el problema de la cultura visual ampliamente tratado por autores como Nicholas Mirzoeff (2003). Para Elkins (2003), entonces, comprender las imágenes como parte de un lenguaje que se aprende significa que "podríamos leer imágenes, analizarlas como si estuvieran escritas, leerlas en voz alta, decodificarlas y traducirlas" (p. 128, traducción propia). En su sentido más básico, para el autor, la alfabetización visual sería la adecuada capacidad para identificar imágenes y analizarlas, también recordarlas, de acuerdo con las formas en que se refieren al mundo, lo que nos dirige al conocimiento; pero que, desde una visión más compleja, no puede excluir la idea de que se trata, en el fondo, de una especie de caja de herramientas de interpretaciones (Elkins, 2003, pp. 137-138). Finalmente, para Elkins, los procesos que implican las técnicas de creación de imágenes sí forman parte de las formas de alfabetización visual. 
Los documentos The Use of Photographs y Training Program se insertan, siguiendo estas ideas conceptuales, en un modelo epistemológico de carácter fotográfico y visual que busca, más allá de una simple estrategia propagandística, socializar y movilizar, por medio de un código particular, un conocimiento específico de uso de las imágenes, en el marco de una noción implícita de alfabetización visual, que le permitió a la compañía cumplir con objetivos comunicativos. El objetivo de este artículo es describir y analizar, desde una perspectiva histórica, los rasgos y características de ese proceso partiendo del abordaje de las propias técnicas de alfabetización visual para el uso de las fotografías que se encuadran, además, en un sofisticado sistema de distribución que está indicado en el Training Program: "DENTRO DE LA EMPRESA: Revistas, Folletos, Informes Anuales"; "EN LAS ESCUELAS: exposiciones, publicaciones, películas de diapositivas"; "EN PUBLICACIONES GENERALES" (Standard Oil Company (New Jersey), n.d.-b, p. 4, traducción propia).

La perspectiva metodológica supuso la definición del objeto en términos de programa de alfabetización visual, entendido como un espacio social e histórico de transformación epistémica. Se delimitó un corpus documental que permitió clasificar, en una base de datos, los documentos internos producidos por la Photographic Section para diferenciar cuáles podían tener un carácter epistémico. El estudio documental concreto se centra en un corpus de fuentes primarias, escritas y visuales, producido por la SONJ, entre 1943 y 1950, ubicadas en el archivo Roy Stryker (1893-1975) Papers. 1912-1972, ubicado en la sección Photographic Archives de la University of Louisville, en Estados Unidos.

Se identifica que dos de los documentos, The Use of Photographs y Training Program, están conectados con distintos tipos de fuentes que soportan todo el proyecto (memorandos, cartas, ensayos, instructivos, informes, artículos 
académicos, notas de prensa, folletos, guías o programas de entrenamiento que el propio archivo produjo para explicar su propio desarrollo). El análisis se centra en la relación entre las técnicas, reglas, instrucciones, recomendaciones y procedimientos del proceso de alfabetización visual, centrado en el uso de las fotografías, con los siguientes núcleos de documentos:

1. Archivo Roy Stryker (1893-1975) Papers. 1912-1972:

- SERIES I. CORRESPONDENCE, 1924-1972.

- SERIES II. PART A - C. 1942-1954.

- SERIES II. PART C - G. 1942-1954.

2. The Lamp Magazine. Archivo Roy Stryker (1893-1975) Papers. 1912-1972. Periodo consultado de 1945 a 1956:

- Revistas consultadas: 40.

3. Revista Lámpara (Colombia). Ref. Biblioteca Luis Ángel Arango, $\mathbf{N}^{\circ}$ Topográfico 682. Periodo consultado de enero de 1952 a diciembre de 1962:

- Volumen: a1952-1955 v1-3 n1-14.

- Volumen: a1956-1959 v4-6 n15-34.

- Volumen: a1959-1962 v7-8 n35-43.

El enfoque metodológico relacional, de tipo documental cualitativo, permitió analizar la conceptualización epistémica del esquema de alfabetización visual, los rasgos de su funcionamiento institucional, la descripción y el examen de las transformaciones de las técnicas propias del dispositivo de conocimiento visual que ponía a prueba, y las formas y modos de difusión y distribución de los resultados. El análisis documental, que relaciona lo textual y lo visual, no implica la imagen como un reflejo de la realidad, como "testimonios", 
como lo dice Burke (2005): "Debería darse cabida también a lo que Francis Haskell llamaba 'el impacto de la imagen en la imaginación histórica'" (p. 16). Las imágenes sirven para construir un esquema de relaciones, que como lo señala Georges Didi-Huberman (2004), incluye toda clase de elementos: "es necesario el cruce constante de los acontecimientos, de las palabras, de los textos" (p. 143).

\section{El dispositivo ilustrado de entrenamiento sobre cómo las fotografías deben ser usadas: las fotografías "hablan"}

El análisis de los documentos, de tipo epistémico, en relación con los usos de las fotografías nos lleva a varios resultados. En primer lugar, en The Use of Photographs se declara, de entrada, la importancia de la fotografía como medio de conocimiento y comunicación que supera las barreras lingüísticas. En la página 2 del documento se muestra una fotografía del campo petrolífero Tía Juana en Venezuela y se señala esa característica de lo fotográfico: "Esta fotografía le habla a los venezolanos acerca del petróleo en Venezuela" y "La misma fotografía le habla a otras personas acerca del petróleo en Venezuela" (Standard Oil Company (New Jersey), n.d.-a, p. 2, traducción propia). A la fotografía se le reconoce como lenguaje de alcance global.

El supuesto de la universalidad del lenguaje fotográfico está desarrollado en otros documentos del esquema. La fotografía se concibe en todos los documentos como un modo de comunicación humana, tal como Allan Sekula (2004) lo explica para otras formas de arte: "El arte, igual que el habla, es tanto un intercambio simbólico como una práctica material consistente en la producción de significado y presencia física" (p. 35). La idea de comunicación encarna una visión epistémica que implica el uso de la fotografía como lenguaje que "le habla" a los espectadores. En "Documentary Photography to Interpret Social and Economic Problems", en una conferencia presentada en 1952, 
Stryker vuelve a resaltar la importancia de la materialidad de la fotografía, pero también, de manera inherente, de la producción del significado, dado que las fotos, para él, son palabras y frases (1952, p. 1 y 2).

En segundo lugar, el uso de las fotografías busca potenciar la combinación entre el estatuto fáctico objetivista y el efecto dramático, emotivo y sentimental que produce la imagen fotográfica (Standard Oil Company (New Jersey), n.d.-a, p. 3, traducción propia). La producción simultánea de realidad y emoción estuvo en el núcleo del programa de entrenamiento visual. La Photographic Section buscó aprovechar simultáneamente el papel de lo fotográfico en torno al uso de fragmentos de evidencia que derivaran en verdades factuales creíbles, y a la construcción de hechos a partir del montaje selectivo de imágenes que afectaran las actitudes emocionales y los recuerdos visuales, como se lee en la página 5 del documento: "Las fotografías son un medio de comunicación eficaz cuando contienen dos elementos principales: la realidad y la emoción" (Standard Oil Company (New Jersey), n.d.-a, p. 5, traducción propia). Para Stryker, la fotografía supera el registro superficial de la realidad y logra construir una representación de la realidad que es simultáneamente densa y esencial y elocuente e intensa. Se debe anotar, eso sí, que el lado expresivo de la imagen documental ha sido fuertemente criticado por especialistas como Sekula (2004, p. 41) o Martha Rosler (2007, p. 254).

En tercer lugar, en la página 6 de The Use of Photographs se presenta una de las recomendaciones más interesantes del dispositivo de entrenamiento visual: "A veces, una fotografía puede contar una historia, pero más a menudo muchas fotografías pueden contarla mejor" (Standard Oil Company (New Jersey), n.d.-a, p. 6, traducción propia). La frase presupone un trabajo de fragmentación visual de la "realidad". Lo que está contenido en una sola fotografía, por ejemplo en plano general, puede comunicarse mejor, narrativamente, a partir de varias 
fotografías. En sentido estricto, se propone una fragmentación del espacio plástico y del tiempo de la acción de la imagen siguiendo nociones propias de montaje visual, cercanas a las teorías de los formalistas rusos.

En el ejemplo de la diapositiva usada para la instrucción se muestra una fotografía en un gran plano general de un exterior de una refinería petrolera con la siguiente frase "Esta imagen intenta decir mucho" (Standard Oil Company (New Jersey), n.d.-a, p. 6, traducción propia). Pero inmediatamente se presenta la propuesta de corrección a partir del ejemplo de la fragmentación en 5 fotografías más específicas que incluyen parte de ese espacio exterior, un primer plano de los detalles, parte de la actividad humana desarrollada en el espacio interior, imperceptible en la imagen en plano general, e imágenes en plano medio del funcionamiento de las máquinas. La instrucción dice: "La misma historia se cuenta mejor como la suma de muchas partes" (Standard Oil Company (New Jersey), n.d.-a, p. 6, traducción propia). En términos de retórica visual, este montaje revela una intención por construir de manera más vívida y experiencial la información de tal modo que el ejercicio de elaboración de imágenes mentales, memorias y recuerdos se tornara más factible a partir de la narración de esas historias (Hill, 2004, p. 31).

El ejercicio de fragmentación de hechos, espacios, historias, situaciones o acciones estaba planteado desde el guion previo de las historias propuestas para que los fotógrafos las construyeran. Estos guiones partían a veces de Stryker, pero otras veces eran propuestos por los mismos fotógrafos. La idea de fragmentar el espacio y el tiempo real y visual resultaba bastante precisa. La historia denominada "Geologist at work" o "Seismograph party", realizada en 1946 en los Llanos de Colombia por el fotógrafo John Collier Jr. para el archivo, se presenta como una secuencia de acción fragmentada en continuidad espacial y temporal, por medio variaciones en tamaños de plano y puntos de vista. 
Estos principios, sobre el efecto del uso de las fotografías, se refuerzan, en la página 7 de The Use of Photographs, al poner el acento en la yuxtaposición de imágenes, otro elemento fundamental para la comunicación visual moderna: "El mensaje en una fotografía a menudo se ve reforzado por imágenes subsidiarias" (Standard Oil Company (New Jersey), n.d.-a, p. 7, traducción propia). En el ejemplo, se muestra una imagen con dos fotografías montadas que expresan una yuxtaposición interesante entre directivos de la compañía y un trabajador de campo, revelando la "diversidad" del trabajo: "una imagen apoyada por un opuesto" (Standard Oil Company (New Jersey), n.d.-a, p. 7, traducción propia). El reforzamiento o construcción de significados visuales por yuxtaposición o por relación entre planos está en la base de la teoría del montaje de cineastas soviéticos como Lev Kuleshov, Vsévolod Pudovkin o Serguéi Eisenstein. De entrada, se reconoce que yuxtaponer dos o más fotografías va a producir la sensación de relación visual en la cual el espectador va a participar para la construcción de los significados, mediante su propia semántica de espacio y tiempo (Stigneev, 2002, p. 97). La preferencia de la fotografía por los patrones de interrelación espacial, patrón del mundo visual moderno, permite que las unidades individuales de información visual se unan en un orden controlado, como lo señala Rudolf Arnheim (2002, p. 41).

Para Howard S. Becker (1982), estos procesos de edición, en los mundos artísticos del siglo XX, suponen un conjunto colectivo de decisiones que le darán a los productos su forma final (p. 194). De ahí la importancia del dispositivo de entrenamiento The Use of Photographs en la socialización de las convenciones de uso de las fotografías para que todos los actores institucionales individuales y colectivos compartan el código. La tarea de edición fotográfica fue parte fundamental del programa de entrenamiento de Stryker. En la página 8 del documento se plantea que la estrategia para atraer la atención o marcar un punto relevante o significativo en una imagen es el recorte ampliado de una parte de la imagen: "Con frecuencia, parte de una imagen se puede utilizar 
para resaltar un punto" (Standard Oil Company (New Jersey), n.d.-a, p. 8, traducción propia). En síntesis, en la cadena de producción de los mensajes fotográficos hay un número amplio, pero limitado, de momentos para tomar decisiones editoriales. Las toma el director cuando plantea las historias, el fotógrafo cuando las ejecuta, el laboratorista cuando procesa las imágenes, o el editor visual de publicaciones cuando monta las secuencias. Para Becker (1982), los patrones que se socializan colectivamente se relacionan también con las operaciones de diseño de la psicología de la Gestalt y las operaciones artísticas que operan de acuerdo a la distribución del conocimiento (p. 41).

Finalmente, en cuarto lugar, la Photographic Section de la SONJ se planteó el problema de las relaciones entre las imágenes fotográficas y las palabras, uno de los más importantes de la historia de la epistemología visual: "Las fotografías y las palabras juntas se dan, entre sí, un significado adicional" (Standard Oil Company (New Jersey), n.d.-a, p. 9, traducción propia). Mitchell (2009) plantea que "Palabra e imagen" es un tipo de distinción ordinaria entre tipos de representación, una manera fácil de dividir, cartografiar y organizar campos de representación (p. 11). Pero insiste en que más que una distinción se trata de una relación histórica cambiante que, aunque supone la existencia de diferencias entre los medios, o entre las palabras y las imágenes resulta compleja: "'Palabra e imagen' es una etiqueta engañosamente simple, no sólo para dos tipos de representación, sino para unos valores culturales profundamente contrastados" (p. 11).

La idea de establecer relaciones comunicativas entre palabras e imágenes resultaba fundamental dado que uno de los objetivos fundamentales era aprovechar los medios de comunicación masiva de la época como revistas, periódicos o películas y los medios que tuvieran impacto institucional directo como libros de texto, exposiciones de arte, panfletos, o folletos. Las frases de The Use of Photographs, con los ejemplos de fotografías en publicaciones 
escritas, "Aquí la fotografía dramatiza las palabras", "Aquí la fotografía y las palabras son unidad" y "Aquí la fotografía soporta las palabras" (Standard Oil Company (New Jersey), n.d.-a, p. 9, traducción propia), suponen unas relaciones dinámicas y técnicas para la construcción de los significados y mensajes. Justamente Mitchell (2009) señala que la interacción entre imágenes y textos es constitutiva de la representación en sí dado que todos los medios son mixtos y "no existen las artes 'puramente' visuales o verbales, aunque el impulso de purificar los medios sea uno de los gestos utópicos más importantes del modernismo" (p. 13).

En el documento, las fotografías pueden dramatizar, ilustrar o apoyar las palabras, pero también pueden constituir una unidad significativa con ellas, para, como lo dice Valery Stigneev (2002), afectar la percepción de los espectadores:

La coexistencia de texto y secuencias visuales lleva a una interacción semántica y plástica, una interacción que funde los significados semánticos introducidos en el texto con el tema gráfico de la imagen. (...) Este proceso presupone la interacción de textos verbales y visuales, su influencia mutua, y la vida del uno a través del otro. (p. 96)

Para Stryker, por una parte, la fotografía, al ser entendida como comunicación, compartía rasgos con otros medios, lenguajes u objetos de representación que le permitían contar historias, construir argumentos, realizar ensayos, informar. Pero, por otro lado, creía en que al relacionar las fotografías, los textos, las pinturas o el cine se potenciaba y se ampliaba esa posibilidad de comunicación.

Siguiendo la noción de imagentexto de Mitchell sobre por qué es importante la forma en que las palabras y las imágenes se yuxtaponen, se mezclan o se separan, The Use of Photographs propone una combinación complementaria entre textos e imágenes, en los que el peso epistémico parece recaer en el texto con funciones determinadas: dramatizar, ilustrar, soportar. Pero también avanza 
sobre la creación de equivalencias en la función de lo visual en relación con lo verbal: fotografías y palabras son una unidad. En el caso del ensayo fotográfico, según Mitchell (2009) por ejemplo, la:

(...) estructura normal de este tipo de imagentexto conlleva una sutura narrativa o discursiva directa de lo verbal y lo visual: los textos explican, narran, describen, etiquetan, hablan en nombre de (o a) las fotografías; las fotografías ilustran, ejemplifican, aclaran, fundamentan y documentan el texto. (pp. 87-88)

Se trata de relaciones intercambiables y se vuelven inseparables en su uso. Esto coincide, de manera precisa, con los análisis del mensaje fotográfico, por ejemplo para la imagen periodística, propuesto por Roland Barthes (1986) que insiste en que la estructura de la fotografía está lejos de ser una estructura aislada: "mantiene, como mínimo, comunicación con otra estructura, que es el texto (titular, pie o artículo) que acompaña siempre a la fotografía de

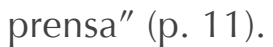

\section{El programa de entrenamiento visual para la distribución de las fotografías}

Las historias fotográficas se expandían en varios medios y en múltiples plataformas, buscando llegar a un conjunto fragmentado de usuarios, a escalas local y global, implicadas en los campos corporativo, educativo y artístico y en los medios de comunicación. Desde "Attached are a few notes on what I think should be done, and the way it could be accomplished" (Stryker, 1943), el primer documento elaborado en el marco de la construcción y desarrollo de la Photographic Section de la SONJ, se conectó la producción fotográfica con un conjunto de usos mixtos soportados en un amplio proceso de distribución, difusión y apropiación de las imágenes que involucraba otros lenguajes. Las fotografías que la compañía realizó en todos los lugares del mundo donde envió fotógrafos llegarían así a toda clase de usuarios, tanto 
comunes —educadores, estudiantes, empleados, familias, empresas, etc.- , como especializados —editores, autores, casas editoriales o investigadores(Stryker, 1943, p. 2).

La propuesta inicial de distribución definía tres tipos generales de difusión: dentro de la propia compañía —revistas, folletos y panfletos, reportes anuales-, en escuelas y colegios —exhibiciones, libros escolares, recursos educativos, presentaciones de diapositivas - , y en publicaciones para medios masivos escritos y visuales (Standard Oil Company (New Jersey), n.d.-b, p. 4). De entrada, el reto de distribuir el material fotográfico en el sistema educativo implicaba un cambio sustancial en los enfoques de la época de los programas de comunicación para una corporación privada.

La compañía replanteó la función de las publicaciones existentes como la revista The Lamp, fundada en 1918 como The Lamp, a magazine for Jersey employees, que, ahora, se pondrían al servicio de esa nueva visión que suponía un replanteamiento en los procesos de comunicación, más allá de las estrategias propagandísticas y publicitarias del momento. El sistema de distribución comenzó a utilizar nuevas estrategias gramaticales y editoriales, y nuevos y variados mecanismos y formatos de circulación soportados en distintas plataformas, internas y externas de la compañía, con alcance tanto local como global. El programa de publicaciones creció notablemente durante este periodo, y la revista The Lamp se convirtió en una de las referencias en la comunicación empresarial. A partir de 1943 la publicación comenzó a utilizar de manera sistemática imágenes visuales. Se siguió utilizando la pintura y el dibujo, como se observa en la revista de septiembre de 1944 (The-Lamp, 1944), pero fue a partir del desarrollo del archivo que la revista se convirtió en una publicación que combinaba de muchas maneras imágenes fotográficas y palabras. 
Uno de los públicos más relevantes para la compañía eran sus propios empleados y sus familias. De ahí que se reestructuró el modelo de comunicación interna haciendo énfasis en la idea de que cada trabajador era, al mismo tiempo, toda la compañía. Pero, también, se comenzó a utilizar el lenguaje fotográfico como medio para educar a los empleados respecto al propio funcionamiento de la petrolera e incluso sobre actividades y tareas específicas desarrolladas en el proceso industrial:

Las imágenes también son persuasivas para informar a los empleados sobre nuevos desarrollos en su propia empresa o industria. Standard Oil Company (Nueva Jersey) tiene un servicio regular que trae fotografías instructivas a los hombres y mujeres que elaboran sus productos. Estas historias pueden aplicarse directamente a trabajos específicos o esbozar las tendencias de la industria en términos más amplios. (Standard Oil Company (New Jersey), n.d.-b, p. 7, traducción propia)

Ese proceso de socialización epistémica alcanzó también a los públicos externos que recibirían las publicaciones y que asistirían a las exposiciones fotográficas. Se buscaba, como lo explica Becker (1982), que la gente del común estuviera "bien socializada" respecto de las características de un lenguaje y un código específico: sus convenciones, sus reglas, su historia, sus géneros, sus estilos (p. 48). Es fundamental señalar que, tanto en Estados Unidos como en Europa y América del Sur, la Photographic Section de la SONJ buscó conectarse con las élites artísticas e intelectuales de la época, a quienes contrataba como asesores o directamente como editores visuales, buscando, por una parte, aumentar la calidad estética de los productos y publicaciones y, por otro lado, aprovechar el prestigio y la distinción que tenían esos actores sociales específicos. Además de la distribución especializada se logró llegar a públicos y usos muy cotidianos:

Las fotografías llegaron a ser solicitadas por ilustradores de revistas y por el departamento de investigación de los estudios cinematográficos. Pero todos se sorprendieron cuando algunas de las imágenes se utilizaron como decoración de interiores en forma de fotomurales en aviones y para ilustrar un libro sobre el clima. (Public Relations Department. Standard Oil Company (N.J.)., n.d., p. 6, traducción propia) 
En 1949, año del informe técnico, el acervo de la SONJ, que contenía más de 55.000 fotografías catalogadas disponibles para su uso, era considerado por la compañía como un servicio público (Public Relations Department. Standard Oil Company (N.J.)., n.d., p. 8). De ahí que el proceso de distribución se definiera, desde su concepción, como gratuito, al que cualquier institución o persona natural podía acceder tras Ilenar un formulario con la información sobre las imágenes requeridas, la identificación del solicitante y la descripción del uso de la imagen, dando, solamente, el crédito correspondiente.

El resumen estadístico entregado por el informe técnico revela que en 1949 se habían impreso el significativo número de 46.206 fotografías para usuarios concretos que luego las difundirían en sus canales y medios de comunicación, distribuidas así: Jersey and affiliates (31.369), Newspapers and Rotogravure (1.143), Magazines (6.725), Books and Encyclopedias (2.032), Miscellaneous: Exhibits, Slide films, Advertising (4937). Asimismo, el informe refleja que en ese año el número de consultas directas en el acervo alcanzó las 821 visitas y un número de 590 solicitudes por otros medios: telefónico o escrito. Se destaca, particularmente, la consulta de la publicación PHOTO MEMO que, como se explicará más adelante, sintetizaba la búsqueda de la SONJ por poner al lenguaje fotográfico como el eje de la comunicación institucional (Public Relations Department. Standard Oil Company (N.J.)., n.d., p. 9).

\section{Fotografías, arte y educación visual}

Es importante señalar que uno de los efectos de este sistema de distribución estaba relacionado con el estatus y el reconocimiento de los fotógrafos, tanto el que ellos aportaban al esquema, como el que el archivo les aportaba a ellos, dada su envergadura e impacto. Las fotografías de la SONJ también circularon por grandes medios editoriales (Plattner, 1983, p. 21). El sistema de distribución 
hizo posible que las fotografías de la SONJ Ilegaran a las publicaciones visuales más importantes de la época y a los grandes museos de Estados Unidos:

\begin{abstract}
En el aspecto cualitativo de la distribución, cabe mencionar que las fotografías de Jersey han aparecido en la mayoría de revistas de circulación nacional, entre ellas VOGUE, SATURDAY EVENING POST, TIME, LIFE, FORTUNE. Se han exhibido en museos destacados de la nación, incluido EL MUSEO DE ARTE MODERNO, el MUSEO DE CIENCIA E INDUSTRIA de Chicago y el INSTITUTO FRANKLIN en Filadelfia, donde el director declaró que la calidad de la fotografía de jersey había cambiado de opinión favorablemente sobre las exhibiciones fotográficas. (Public Relations Department. Standard Oil Company (N.J.)., n.d., p. 9 y 10, traducción propia)
\end{abstract}

A partir de 1943, The Lamp se convirtió en una revista gráfica soportada en la construcción de un lenguaje que articulara de manera integral el lenguaje visual y el lenguaje textual. El modelo editorial de The Lamp, desde el punto de vista de los usos de las imágenes, coincidía, en sentido general, con el de las publicaciones gráficas más importantes del mundo como las revistas Life, Fortune y Vogue. Para Gisèle Freund (2004), el éxito de la prensa ilustrada de ese momento, como en el caso de Life que se fundó el 23 de noviembre de 1936, que llegó a un millón de ejemplares en 1937 y que alcanzó la cifra de 40 millones de lectores norteamericanos por número, estaba en el uso sistemático y riguroso de la imagen fotográfica (p. 129).

En el caso de The Lamp se creó una relación racional especializada, sintetizada en sus historias y soportada en imágenes fotográficas, entre la economía, la sociedad y la cultura. La revista buscó mostrar cómo el "mundo del petróleo" conectaba con aspectos sociales y culturales de todo tipo. Mediante las historias visuales, los fotógrafos trataron de dar cuenta de esa relación que, por supuesto, puede leerse en sentido mitológico: "En todas estas publicaciones, así como en muchas otras de índole similar, la característica principal es que las fotografías afirman su independencia. No se trata de ilustraciones. Transportan su mensaje como lo hace el texto" (Newhall, 2002, p. 246). 
The Lamp, como Life, utilizó distintos tipos de imágenes visuales para ilustrar sus historias. Grandes artistas ilustraron sus páginas. Pero también la revista comenzó a emplear profesionales reconocidos en diversos campos artísticos para fortalecer sus publicaciones. En The Lamp escribieron importantes periodistas, ensayistas y literatos, y contribuyeron políticos y académicos de distintas partes del mundo. Así se comenzó a consolidar un canon editorial para las publicaciones corporativas:

Se han convertido en revistas interesantes y lujosas, publicadas con gran esmero. Escritores y periodistas famosos son los autores de sus artículos, mientras que sus reportajes fotográficos corren a cargo de grandes fotógrafos muy bien pagados. Cientos de revistas de este género aparecen en Estados Unidos. Electronic Age, por ejemplo, es una publicación de la R.C.A. (Radio Corporation of America). La Standard Oil publica una revista bajo el nombre The Lamp. (Freund, 2004, p. 134)

El éxito de The Lamp llevó a la SONJ a replicar este programa de publicaciones por medio de sus filiales en otros países e idiomas, lo que denota la búsqueda de un alcance global en su sistema de distribución y las formas de adaptación de los contenidos, incluyendo los visuales, a los públicos locales. Los casos más Ilamativos son la revista bimensual Lámpara, creada en 1952 por la International Petroleum (Colombia) en Colombia, en asocio con la Esso colombiana y la Andian National Corporation; y la revista El Farol, creada, por la misma época, por la Creole Petroleum Corporation en Venezuela. Estas publicaciones se convirtieron en una referencia revolucionaria para la historia de los medios gráficos y visuales en estos países, y utilizaron un modelo editorial idéntico al de la revista madre (Larson et al., 1971, p. 643). PHOTO MEMO fue otra publicación seriada en la que el lenguaje fotográfico tenía la máxima preponderancia. Era un órgano de difusión directa de la Photographic Section, publicación que Steven W. Plattner (1983) consideraba fundamental (p. 21). En cada número se ofrecía una definición de su sentido, uso y contenido, y se buscaba que el público conociera el acervo fotográfico 
para su uso gratuito y abierto. El número 3, por ejemplo, abre con una historia sobre Colombia (PHOTO-MEMO, 1947).

El sistema de distribución buscó conectarse intensamente con el campo educativo. El texto del panel sobre "Education", del programa de entrenamiento visual, sintetiza el sentido que la compañía buscaba darle al uso de las imágenes fotográficas con fines educativos que, por supuesto, estaban enmarcados en la mitología propuesta por la compañía dentro del marco de un proyecto de relaciones públicas: se pretendía que los niños aprendieran por medio de imágenes más sobre el mundo a su alrededor y, en el camino, reconocieran la importancia del petróleo para su futuro. Los mecanismos de distribución resultaban directos y novedosos, siguiendo una sofisticada línea intermedial, e incluían el uso de soportes como presentaciones o películas de diapositivas, slidefilms, o presentaciones en lighbox que se llevaban a los salones de clase:

Las escuelas tienen un interés constante en las imágenes que ayudan a los niños a aprender más sobre el mundo que los rodea. Muchas de las historias con imágenes documentales realizadas para Jersey Standard se han reproducido en paneles educativos (el ejemplo se muestra en la caja de luz), en diapositivas o en folletos destinados a la distribución en el aula. (Standard Oil Company (New Jersey), n.d.-b, p. 6, traducción propia)

Pero el sistema de distribución contemplaba, también, el impacto, a largo plazo, de las imágenes fotográficas en los libros de texto, incluyendo enciclopedias, principalmente de geografía, historia, economía y ciencias naturales, con el objetivo de que las historias fotográficas, de distintas partes del mundo y de Estados Unidos, adquieran un valor institucional en el imaginario colectivo, por supuesto acompañadas del crédito de la SONJ. La Photographic Section recibió, además, solicitudes para libros sobre el clima, atlas geográficos, calendarios y publicaciones que buscaran producir efectos visuales. Se buscaba llegar a los estudiantes utilizando recursos comunicativos como los paneles de imágenes o las presentaciones fílmicas: 
Para uso escolar especial, hemos completado recientemente una serie de diez paneles, que contienen fotografías, otros materiales visuales y texto impreso, que relatan gráficamente los dramas de petróleo. Los paneles se utilizarán como exposición para su circulación entre los cientos de escuelas que han solicitado material educativo sobre el tema. (Stryker, n.d., p. 7, traducción propia)

Las filiales y socias de la propia SONJ también solicitaban material constantemente para sus publicaciones o exhibiciones. La evidencia de las buenas relaciones entre la compañía y el gobierno de Estados Unidos, y el deseo de la SONJ de incluir al Estado en parte de su estrategia, también se refleja en el interés que tenía la organización en aportar a las políticas de relaciones internacionales con los países latinoamericanos. Se comenzaron a gestionar intercambios de historias visuales con los países de América Latina, preferiblemente donde estaban sus empresas filiales, con la intermediación de la división de cultura del Departamento de Estado de los Estados Unidos para realizar exhibiciones y "shows". La carta que envía, el 9 de mayo de 1959, G. M Crookston, de la Tropical Oil Company en Colombia, a su casa madre la International Petroleum Co, en Canadá, filial de la SONJ, revela, por ejemplo, el interés que se tenía desde Colombia por usar las fotografías de la Photographic Section. La carta pide autorización para que el Ministerio de Comercio de Colombia pueda usar las fotografías en el pabellón de Colombia en una feria internacional en Chicago. Se solicita enviar las fotografías desde Nueva York al lugar de la exposición (Crookston, 1950).

Pero el sistema de distribución también estableció una dinámica relación con el campo artístico y sus propias estrategias comunicativas. Se utilizó, sistemáticamente, la estrategia de las exposiciones y exhibiciones fotográficas en sala para difundir las fotografías en museos, instituciones educativas y empresas, utilizando las convenciones de las exhibiciones de arte y el uso de paneles, cuadros y series articulados mediante estructuras narrativas curatoriales. Los recortes de periódico, guardados como prueba de la realización de los eventos, muestran que las exposiciones tienen distintas 
funciones y contenidos y se ofrecen en distintos lugares de Estados Unidos. La estrategia se sigue revelando, por ejemplo, en la exposición fotográfica "Hands", a pictorial essay, realizada en The Mint Museum of Art, como se lee en el periódico The Charlotte News del 7 de junio de 1947. Tanto el museo The Cleveland Museum Of Natural History como Chicago Natural History Museum aceptaron incluir en sus colecciones y exhibiciones los paneles de las historias de la Photographic Section de la SONJ, resaltando su valor educativo.

Así mismo, el 26 de marzo de 1948, el Audio-Visual Materials Consultation Bureau, de la Wayne University, le envió a Roy E. Stryker una evaluación de los paneles de exhibición que se usaban para una de sus exposiciones principales: "The Story of Oil". Los paneles fotográficos fueron calificados como atractivos, informativos y aceptables para el uso educativo. Stryker buscaba que el material fotográfico, producido para los distintos usos, tuviera el reconocimiento profesional de todos los campos en los cuales el sistema de distribución tuviera impacto. En este caso, Stryker pretendía que una organización de educación superior, experta en material audiovisual, validara el material tanto en su función como en su forma para el uso educativo y pedagógico. Las fotografías son evaluadas como de alto estándar. La institución valoró el color, el formato, los textos y los títulos de la exposición fotográfica; y recomendó un uso educativo en salones de clase, que incluyera guías para el trabajo del profesor con los estudiantes (Audio-Visual Materials Consultation Bureau. Wayne University, 1948).

En síntesis, el sistema de distribución buscó adecuarse a funciones educativas enfocadas tanto en el público general como en la educación formal básica, para Estados Unidos, principalmente en el ámbito de lo histórico y lo artístico. Para Stryker, la relación epistémica entre fotografía y educación debía estar conectada con el trabajo de los científicos tanto sociales como naturales, e integrada a las instituciones sociales, económicas, culturales y políticas 
de la sociedad. Como lo señala Elkins (2008): "La alfabetización visual o alfabetizaciones - el plural será un problema en todo momento- son tan importantes para la educación de nivel universitario como la alfabetización (ordinaria), y se discuten con mucha menos frecuencia" (p. 1, traducción propia).

\section{Conclusiones}

El artículo revela que la Photographic Section de SONJ logró producir un conjunto de metadocumentos textuales y visuales que revolucionaron la epistemología visual en entornos industriales y alimentaron un ejercicio de racionalidad epistémica sostenido por un dispositivo fotográfico. Los documentos analizados, como guías de entrenamiento y manuales de instrucciones, desarrollan, en su propio contexto histórico, conceptos, metodologías y técnicas sobre el uso de las fotografías para distintos tipos de efectos funcionales, incluyendo la propia educación visual. En este sentido, el trabajo realizado por Stryker se constituye en un esfuerzo pionero, totalmente desconocido por los historiadores que posteriormente estudiaron estos temas, en el desarrollo de técnicas de alfabetización visual. La propia noción de uso de fotografías fue, apenas, comprendida mucho tiempo después en la reflexión historiográfica. Así mismo, el esquema es revolucionario en la comprensión epistémica de la relación entre las imágenes fotográficas y las palabras, superando muy tempranamente una distinción y discusión ordinaria entre dos tipos de representación que resultan históricamente inseparables en el uso social.

Se analizó, además, el sistema de distribución visual de la Photographic Section de la SONJ, el cual generó una estrategia de diseminación, inédita en la comunicación corporativa, de historias visuales-textuales en varios medios y en múltiples plataformas de tal manera que los mensajes se transformaran de una u otra forma para llegar a las audiencias, locales y globales, por distintas 
vías, dada la época, con el concurso del propio público, interno o externo a la compañía, en ámbitos específicos: empresarial, educativo, artístico. La propia noción de imagentexto parece tener lugar, en este esquema, respecto a la forma como las imágenes fotográficas se relacionan con las palabras de maneras complejas e imbricadas, contra la tendencia, empírica y teórica, que busca separar los lenguajes en su uso y práctica comunicativa. En este sentido, este artículo muestra que muchos de los supuestos que caracterizan la epistemología de la comunicación contemporánea, en torno a las estrategias de distribución intermediales, ya aplicaban para casos como este, más allá de la terminología usada mucho después.

\section{Referencias}

Arnheim, R. (2002). Estudio sobre el contrapunto espacial. En S. Yates (Ed.), Poéticas del espacio (pp. 33-50). Gustavo Gili.

Audio-Visual Materials Consultation Bureau. (1948). Evaluation of Panels Presenting "The Story of Oil". Wayne University. ROY STRYKER (1893-1975) PAPERS 1912-1972, 78.9 SERIES II, C-G, BOX 7, FOLDER 4, SONJ-EXHIBITS. II-D.4. Photographic Archives. Special Collections and Archives. University of Louisville. Louisville, KY.

Barthes, R. (1986). Lo obvio y lo obtuso. Paidós.

Becker, H. S. (1982). Art Worlds. University of California Press.

Bourdieu, P. (2003). Un arte medio. Gustavo Gili.

Brea, J. L. (2005). Los estudios visuales: por una epistemología política de la visualidad. En J. L. Brea (Ed.), Estudios Visuales. La epistemología de la visualidad en la era de la globalización. Akal.

Burke, P. (2005). Visto y no visto. El uso de la imagen como documento histórico. Crítica.

Didi-Huberman, G. (2004). Imágenes pese a todo. Memoria visual del Holocausto. Paidós.

Elkins, J. (2003). Visual Studies. Routledge. 
Elkins, J. (2008). Introduction The Concept of Visual Literacy, and Its Limitations. In J. Elkins (Ed.), Visual Literacy (pp. 1-10). Routledge.

Freund, G. (2004). La fotografía como documento social. Gustavo Gili.

Gombrich, E. H. (2002). Arte e ilusión. Estudio sobre la psicología de la representación simbólica. Phaidon.

Gombrich, E. H. (2003). Los usos de las imágenes. Estudios sobre la función social del arte y la comunicación visual. Fondo de Cultura Económica.

Goyeneche-Gómez, E. (2020). El poder del archivo fotográfico "anti-icónico" y su efecto histórico de representación: Sudamérica en el mapa global moderno. Arte, Individuo y Sociedad, 32(2), 345-361. https://doi.org/10.5209/aris.63408

Goyeneche-Gómez, E. (2021). Las relaciones públicas, la comunicación visual y el mito del capitalismo transnacional (1943-1950). Historia Contemporánea, (66), 493-522. https://doi. org/10.1387/hc. 21124

Hill, C. A. (2004). The Psychology of Rhetorical Images. In C. Hill \& M. Helmers (Eds.), Defining Visual Rhetorics. LEA.

Larson, H., Knowlton, E., \& Popple, C. (1971). New Horizons 1927-1950. History of Standard Oil Company (New Jersey). Harper \& Row, Publishers.

Mirzoeff, N. (2003). Una introducción a la cultura visual. Paidós.

Mitchell, W. J. T. (2003). Mostrando el ver. Una crítica de la cultura visual. Estudios Visuales, (1).

Mitchell, W. J. T. (2009). Teoría de la imagen. Akal.

Newhall, B. (2002). Historia de la fotografía. Gustavo Gili.

PHOTO-MEMO. (1947, August). Hands. PHOTO MEMO: From the Picture Files of the Standard Oil Co. (N.J.). [Publicación Interna]. 4.

Plattner, S. W. (1983). Roy Stryker: U.S.A., 1943-1950: The Standard Oil (New Jersey) Photography Project. University of Texas Press.

Public Relations Department. Standard Oil Company (N.J.). (n.d.). Photographic Section. [Manuscrito inédito]. ROY STRYKER (1893-1975) PAPERS 1912-1972, 78.9 SERIES II. PART C - G, BOX 7, FOLDER 3, SONJ. II-D.1. Photographic Archives. Special Collections and Archives. University of Louisville. Louisville, KY. 
Rosler, M. (2007). Imágenes públicas. La función política de la imagen. Gustavo Gili.

Sekula, A. (2004). Desmantelar la modernidad, reinventar el documental. Notas sobre la política de la representación. En J. Ribalta (Ed.), Efecto real. Gustavo Gili.

Standard Oil Company (New Jersey). (n.d.-a). The Use of Photographs. ROY STRYKER (18931975) PAPERS. 1912-1972. 78.9 SERIES II. C-G. BOX 7. FOLDER 5. SONJ-EXHIBITS. IID.4. Photographic Archives. Special Collections and Archives. University of Louisville. Louisville, KY.

Standard Oil Company (New Jersey). (n.d.-b). Training Program. ROY STRYKER (1893-1975) PAPERS 1912-1972, 78.9 SERIES II, C-G, BOX 7, FOLDER 5, SONJ-EXHIBITS. II-D.4. Photographic Archives. Special Collections and Archives. University of Louisville. Louisville, KY.

Stigneev, V. (2002). El texto en el espacio fotográfico. En S. Yates (Ed.), Poéticas del espacio (pp. 95-106). Gustavo Gili.

Stryker, R. E. (n.d.). [Manuscrito inédito]. ROY STRYKER (1893-1975) PAPERS. 1912-1972. 78.9 SERIES II. A-C. BOX 6. FOLDER 2. RES PERSONAL. II-B-1. Photographic Archives. Special Collections and Archives. University of Louisville. Louisville, KY.

Stryker, R. E. (1943). MEMORANDUM.TO: MR. EARL NEWSOM. FROM: ROY STRYKER. Attached are a few notes on what I think should be done, and the way it could be accomplished. ROY STRYKER (1893-1975) PAPERS 1912-1972, 78.9 SERIES I, Correspondence 1942-1948, BOX 4, Folder 5, 1943, JUL-DIC. Photographic Archives. Special Collections and Archives. University of Louisville. Louisville, KY.

Stryker, R. E. (1952). "Documentary Photography to Interpret Social and Economic Problems". Notes for a talk given at a General Staff Meeting of the Social Security Administration (F.S.A.), Thursday, May 22nd at 10:30 A.M. 1952. ROY STRYKER (1893-1975) PAPERS. 1912-1972. 78.9 SERIES II. A-C. BOX 6. FOLDER 2. RES PERSONAL. II-B-1. Photographic Archives. Special Collections and Archives. University of Louisville. Louisville, KY.

The-Lamp. (1944, September). Oil Notes. The Lamp [Publicación Interna], 26(5).

Wittgenstein, L. (1999). Investigaciones filosóficas. Altaya.

Cómo citar: Goyeneche-Gómez, E. (2022). Un programa de alfabetización visual para el uso y distribución de fotografías: la epistemología visual en el núcleo de una corporación privada. Revista KEPES, 19(25), 79-105. https://doi.org/10.17151/kepes.2022.19.25.4 